\title{
Inactivation of class II transactivator by DNA methylation and histone deacetylation associated with absence of HLA-DR induction by interferon- $\gamma$ in haematopoietic tumour cells
}

\author{
Y Morimoto', M Toyota ${ }^{*, 1,2}$, A Satoh', M Murai', H Mita', H Suzuki', Y Takamura ${ }^{3}$, H Ikeda $^{3}$, T Ishida', N Sato $^{3}$, \\ T Tokino ${ }^{2}$ and $K$ Imai $^{1}$
}

'First Department of Internal Medicine, Sapporo Medical University, South I, West 17, Chuo-ku, Sapporo 060-8543, Japan; ${ }^{2}$ Department of Molecular Biology, Cancer Research Institute, Sapporo Medical University, South I, West 17, Chuo-ku, Sapporo 060-8543, Japan; 'Department of Pathology,

Sapporo Medical University, South I, West 17, Chuo-ku, Sapporo 060-8543, Japan

By presenting immunogenic peptides at the cell surface, major histocompatibility complex (MHC) class II molecules play a key role in the control of adaptive immune responses. Whether expressed constitutively or induced by interferon- $\gamma$, expression of MHC class II molecules is regulated via coactivator class II transactivator (CIITA); moreover, suppression of their expression is one mechanism by which cancer cells escape host immunity. In this study, we surveyed the relationship between the expression of one MHC class II antigen, HLA-DR, and its coactivators in a group of haematopoietic cell lines, and explored the role of the aberrant DNA methylation in silencing HLA-DR expression. Among 26 cell lines studied, HLA-DR expression was lost from eight T-cell and two myeloid leukaemia cell lines, and this loss was closely associated with suppression of CIITA-PIV expression. Notably, nine of the 10 cell lines that lost CIITA-PIV expression showed methylation of the gene's 5' CpG island. Thus, DNA methylation is believed to inhibit the expression of MHC class II molecules in haematopoietic tumour cells by silencing its coactivator, CIITA-PIV. Furthermore, methylation of CIITA-PIV was detected in seven of 32 primary acute myeloid leukaemia specimens, indicating that epigenetic alteration is not a cell line-specific phenomenon. Collectively, these data suggest that, by suppressing expression of MHC class II molecules, epigenetic inactivation of CIITA provides a survival advantage to a subset of haematopoietic tumours.

British Journal of Cancer (2004) 90, 844-852. doi:I0.1038/sj.bjc.660I 602 www.bjcancer.com

(c) 2004 Cancer Research UK

Keywords: transcriptional coactivator; DNA methylation; histone acetylation

By presenting immunogenic peptides at the cell surface, major histocompatibility complex (MHC) class II molecules play a key role in the control of adaptive immune responses (Cresswell, 1994). Moreover, increasing evidence indicates that the ability of $\mathrm{CD} 4+\mathrm{T}$-cells to recognise tumour cells by the MHC class II molecules on their surface enables CD4 + T-cells to contribute to antitumour immune responses; consequently, the absence of MHC class II molecules likely diminishes the antitumour activity of CD4 + T-cells (Ossendorp et al, 2000; Wang, 2001). Constitutive expression of MHC class II is limited to specific immune cell types, such as antigen-presenting and dendritic cells. However, their expression can be induced in nonimmune cells that do not constitutively express them by interferon- $\gamma$ (IFN- $\gamma$ ).

Expression of MHC class II molecules is also regulated by class II transactivator (CIITA) (Mach, 1999), which does not bind to DNA but acts as a coactivator, interacting with DNA-binding transcription factors such as regulatory factor X (RFX) family, NF$\mathrm{Y}$ and CREB (Scholl et al, 1997; Zhu et al, 2000). Transcription of CIITA is regulated by CIITA promoters (CIITA-P) I-IV, each of

*Correspondence: M Toyota; E-mail: mtoyota@sapmed.ac.jp Received 3 August 2003; revised 24 November 2003; accepted 27 November 2003 which directs the expression of a unique first exon (MuhlethalerMottet et al, 1997): CIITA-PI is active primarily in dendritic cells and murine macrophages (Waldburger et al, 2001); CIITA-PII has been identified only in human cells, and its function remains unknown; CIITA-PIII is primarily responsible for directing constitutive expression of CIITA in B cells, and can drive CIITA expression after IFN- $\gamma$ stimulation in endothelial cells, fibroblasts or melanocytes (Piskurich et al, 1998; Deffrennes et al, 2001), and CIITA-PIV is a major regulator of IFN- $\gamma$-inducible expression of CIITA (Muhlethaler-Mottet et al, 1997).

Haematopoietic tumours often show genetic alterations such as nonrandom chromosomal translocations and gene deletion or amplification. In addition, epigenetic modifications of the DNA, which do not alter the sequence code, are now recognised to contribute to the malignant phenotype. For instance, somatic changes in the methylation of CpG dinucleotides commonly occur during the pathogenesis of human tumours (Jones and Baylin, 2002). Among haematopoietic tumours, aberrant methylation of promoter-associated CpG islands (CGIs) in oestrogen receptor, p16INK4A, p15INK4B, p73, p57KIP2 and DAP kinase has been observed in acute lymphocytic leukaemia (ALL), acute myeloid leukaemia (AML), malignant lymphoma and multiple myeloma (Herman et al, 1997; Katzenellenbogen et al, 1999; Garcia-Manero et al, 2002a, b; Li et al, 2002). Methylation-mediated silencing of 
genes involved in immune system function has not been reported in haematopoietic tumours, however.

It is now known that some haematopoietic tumour cells do not express the MHC class II antigen HLA-DR (Kraiba et al, 1989; Wetzler et al, 2003), though the reason why remains unclear. In the present study, we examined expression HLA-DR and coactivators of MHC class II molecules, as well as the effects DNA methylation and histone deacetylation, in a group of human haematopoietic tumour cell lines. Our data suggest that aberrant methylation and histone deacetylation of the region around the transcription start site of CIITA-PIV are closely associated with the absence of IFN- $\gamma$ induced expression of CIITA-PIV, which in turn causes absence of HLA-DR induction in haematopoietic tumour cells.

\section{MATERIALS AND METHODS}

\section{Cell lines and specimens}

DNA and RNA were prepared from eight T-cell ALL cell lines (Jurkat, Molt4, CCRF-HSB2, CCRF-CEM, SupT1, PEER, TALL1, Molt3), six B-cell ALL cell lines (BALL1, CCRF-SB, TOM1, LB804, NALM21, NAGL-1), five multiple myeloma cell lines (HS-Sultan, KMS-12PE, RPMI8226, KHM-1B, U266B1), four myeloma cell lines transformed by Epstein-Barr virus (TAPC, IM9, KR12, RPMI1788), one malignant lymphoma cell line (Raji) and two myeloid leukaemia cell lines (K562, KG1). TOM1, LB804 and NALM21 were kindly provided by Dr Ken Kondo of Hokkaido University, Dr Pierre G Coulie of Ludwig Institute for Cancer Research and Dr Yoshinobu Matsuo of Hayashibara Biochemical Labs, respectively. Other cell lines were obtained from the American Type Tissue Culture Collection or the Japanese Collection of Research Bioresources (Tokyo, Japan). In addition,
32 primary acute myeloid leukaemia specimens used for methylation analysis were described previously (Toyota et al, 2001). To promote the expression of MHC class II molecules, cells were treated with $100 \mathrm{U} \mathrm{ml}^{-1}$ of IFN- $\gamma$ for $48 \mathrm{~h}$ prior to their harvest. DNA was extracted using the phenol/chloroform method. Total RNA was extracted using Isogen (Nippon Gene, Japan), according to the manufacturer's instructions.

\section{Bisulphite treatment}

For bisulphite-PCR, genomic DNA was initially treated with sodium bisulphite (Sigma), as described previously (Clark et al,. 1994), after which $2-\mu \mathrm{g}$ samples were denatured for $10 \mathrm{~min}$ in $2 \mathrm{M}$ $\mathrm{NaOH}$ at $37^{\circ} \mathrm{C}$ before the addition of $30 \mu 1$ of $10 \mathrm{~mm}$ hydroquinone (Sigma Chemical Co. St Louis, MO, USA) and $520 \mu \mathrm{l}$ of $3 \mathrm{~m}$ sodium bisulphite ( $\mathrm{pH}$ 5.0). The mixture was then incubated for $16 \mathrm{~h}$ at $50^{\circ} \mathrm{C}$. The resultant modified DNA was purified using a Wizard DNA Purification System (Promega, Madison, WI, USA), after which it was again treated with $\mathrm{NaOH}$ and precipitated. Finally, the DNA precipitate was resuspended in $20 \mu \mathrm{l}$ of water and stored at $-20^{\circ} \mathrm{C}$ until used.

\section{Combined bisulphite restriction analysis (COBRA) and bisulphite sequencing}

To examine the methylation status of CIITA, COBRA, a semiquantitative analysis of methylation, was carried out as described previously (Xiong and Laird, 1997). Primers for COBRA were designed based on the nucleotide sequences obtained from Genbank (AL591852). Primer sequences are as follows: CIITAGM1-F, 5'-GTAGTTGGGATGTTATTTTTGATAAAG-3'; CIITAGM1-R, 5'-TCTCCCTCCCRCCAACTCT-3'; CIITAGM2-F, 5'-GGT-

T-cell ALL
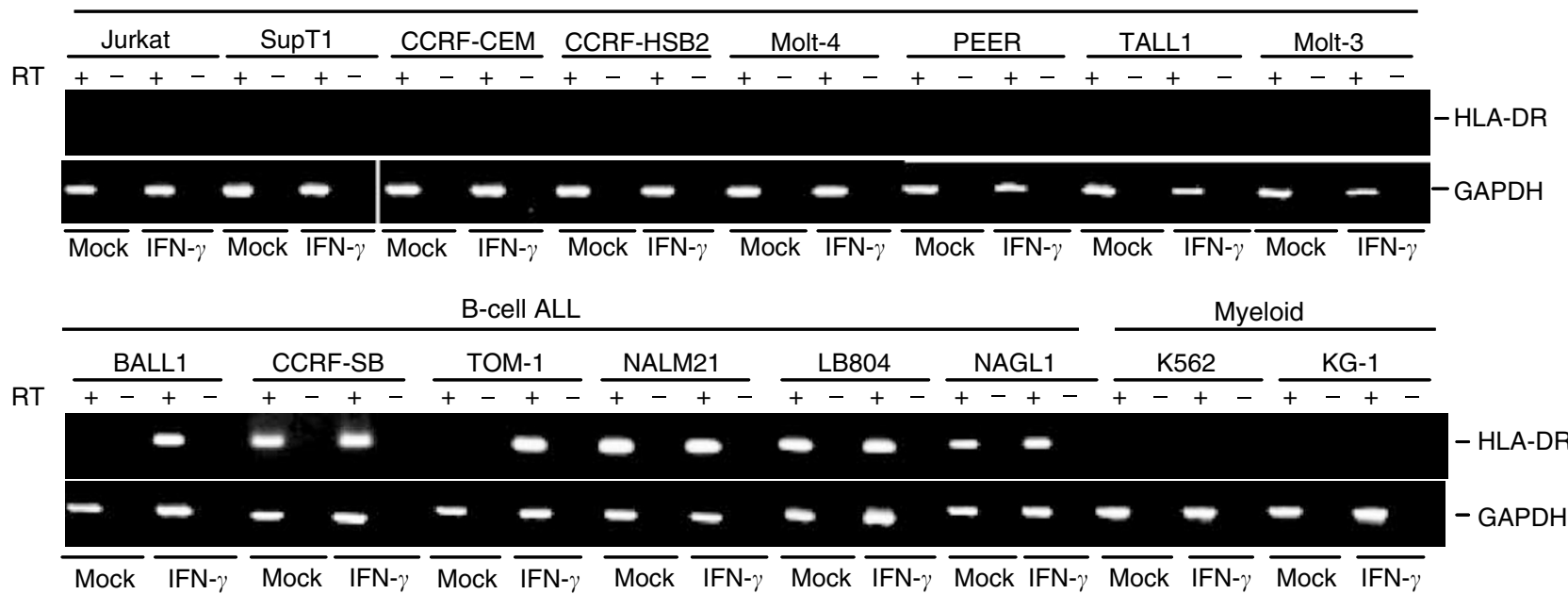

Multiple myeloma

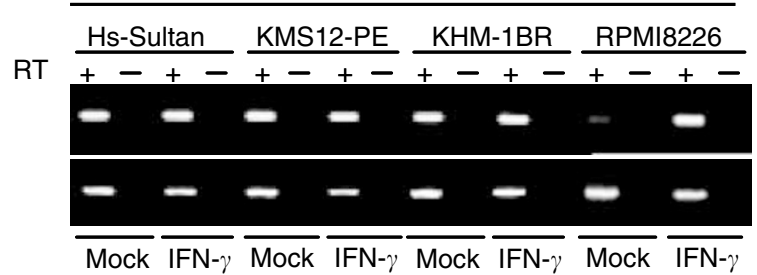

Transformed B cell

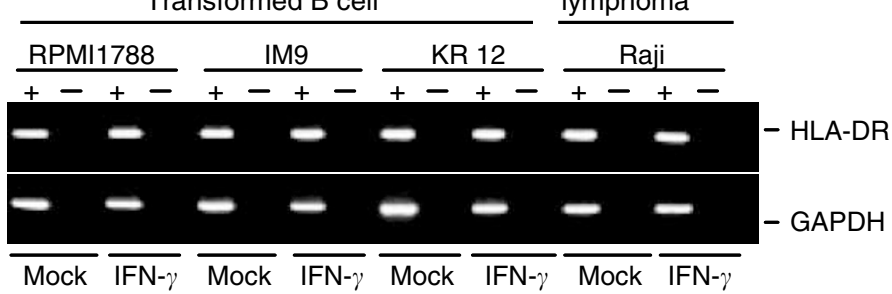

Figure I Expression of HLA-DR in haematopoietic tumour cell lines. RT-PCR was carried out using cDNA prepared from haematopoietic tumour cell lines treated with either mock or $100 \cup \mathrm{ml}^{-1}$ of IFN- $\gamma$ for $48 \mathrm{~h}$. GAPDH was amplified to confirm the integrity of the cDNA. Cell lines and cell types are shown on the top. 
Table I Expression and methylation status of HLA-DR and various types of CIITA in haematopoietic tumour cell lines

\begin{tabular}{|c|c|c|c|c|c|c|c|c|c|}
\hline \multirow[b]{3}{*}{ Cell lines } & \multicolumn{8}{|c|}{ Expression } & \multirow{3}{*}{$\begin{array}{c}\text { Methylation } \\
\text { CIITA-PIV }\end{array}$} \\
\hline & \multicolumn{2}{|c|}{ HLA-DR } & \multicolumn{2}{|c|}{ CIITA-PI } & \multicolumn{2}{|c|}{ CIITA-PIII } & \multicolumn{2}{|c|}{ CIITA-PIV } & \\
\hline & Mock & IFN- $\gamma$ & Mock & IFN- $\gamma$ & Mock & IFN- $\gamma$ & Mock & IFN- $\gamma$ & \\
\hline \multicolumn{10}{|l|}{ B-cell ALL } \\
\hline BALL I & None & +++ & None & None & $0-+$ & + & None & +++ & Unmethylated \\
\hline CCRF-S8 & +++ & +++ & None & None & + & + & +++ & +++ & Unmethylated \\
\hline TOM I & None & +++ & None & None & None & + & None & +++ & Unmethylated \\
\hline LB804ALL & +++ & +++ & None & None & + & + & +++ & +++ & Unmethylated \\
\hline NALM2I $(\mathrm{Ph} \mid+)$ & +++ & +++ & None & None & + & + & +++ & +++ & Unmethylated \\
\hline NAGL-I & +++ & +++ & None & None & + & + & +++ & +++ & Unmethylated \\
\hline \multicolumn{10}{|l|}{ Myeloma } \\
\hline KMSI2-PE & +++ & +++ & None & None & None & None & +++ & +++ & Unmethylated \\
\hline RPMI8226 & + & +++ & None & None & None & None & + & +++ & Unmethylated \\
\hline HS-sultan & +++ & +++ & None & None & None & None & +++ & +++ & Unmethylated \\
\hline KHM-IB & +++ & +++ & None & None & None & None & +++ & +++ & Unmethylated \\
\hline U266BI & +++ & +++ & None & None & None & None & +++ & +++ & Unmethylated \\
\hline \multicolumn{10}{|l|}{ Mature B cell } \\
\hline TAPC & +++ & +++ & None & None & None & None & +++ & +++ & Unmethylated \\
\hline RPMII788 & +++ & +++ & None & None & + & + & +++ & +++ & Unmethylated \\
\hline IM9 & +++ & +++ & None & None & + & + & +++ & +++ & Unmethylated \\
\hline $\mathrm{KRI} 2$ & +++ & +++ & None & None & + & + & +++ & +++ & Unmethylated \\
\hline \multicolumn{10}{|l|}{ T-cell ALL } \\
\hline Jurkat & None & None & None & None & None & None & None & None & Methylated \\
\hline Mot14 & None & None & None & None & None & None & None & 0-+ & Methylated \\
\hline CCRF-HSB2 & None & None & None & None & None & None & None & $0-+$ & Methylated \\
\hline CCRF-CEM & None & None & None & None & None & None & None & $0-+$ & Methylated \\
\hline SupTI & None & None & None & None & None & None & None & None & Methylated \\
\hline PEER & None & None & None & None & None & None & None & $0-+$ & Methylated \\
\hline TALL I & None & None & None & None & None & None & None & None & Methylated \\
\hline Molt3 & None & None & None & None & None & None & None & None & Unmethylated \\
\hline \multicolumn{10}{|l|}{ Burkitt's } \\
\hline Raji & +++ & +++ & None & None & + & + & +++ & +++ & Unmethylated \\
\hline \multicolumn{10}{|l|}{ Myeloid } \\
\hline K562 & None & None & None & None & None & None & None & + & Methylated \\
\hline KG-I & None & None & None & None & None & None & None & None & Methylated \\
\hline
\end{tabular}

+++ : strong expression. +: weak expression. None: no expression.

TATATAGTAAGTTTGGGAGGATG-3'; CIITAGM2-R, 5'-CRACCCCRAAACTCTAAACAC- $3^{\prime}$. The PCR products were digested with restriction enzymes that cleave $C p G$ sites retained because of methylation. After ethanol precipitation, the DNA was subjected to $3 \%$ agarose gel electrophoresis and stained with ethidium bromide. For bisulphite sequencing, the PCR products were amplified using primers CIITA-GM1F and CIITA-SEQR, 5'-ACAATCTCRAAACCTCRATTCTC-3' ${ }^{\prime}$, and cloned into pCR4 vector using a TOPO-TA cloning Kit (Invitrogen), after which the plasmid DNA was purified using a PI system (Kurabo, Tokyo, Japan). Sequencing was carried out using a BigDye Terminator Kit and an ABI 3100 DNA sequencer (Applied Biosystems).

\section{RT - PCR}

The RNA $(5 \mu \mathrm{g})$ was reverse-transcribed using Superscript II (Invitrogen) to prepare first-strand cDNA. Expression of CIITA-PI, PIII and PIV and HLA-DR was assessed using the following primers: CIITAPI-F, 5'-ACTTCCAGGCCATCCTGACT-3'; CIITAPI-R, 5'-GTAGAGGCACAGGGGGTCAGC-3'; CIITAPIII-F, 5'TTCCTACACAATGCGTTGCC-3'; CIITAPIII-R, 5'-TGCTGAACTGGTCGCAGTTGATGG-3'; CIITAPIV-F， 5'- AGACTTGCCGCGGCCCCAGAG-3'; CIITAPIV-R, 5'-GTAGAGGCACAGGGGGTCAGC3'; HLADR-F, 5'-GCCAACCTGGAAATCATGACA-3'; HLADR-R,
5'-AGGGCTGTTCGTGAGCACA-3'; RFX5-F, 5'-AACCACCTGGAAGAGCACACTGAC-3'; RFX5-R, 5'-CCAGGCAGGGGTGGCATAGA-3'; RFXAP-F, 5'-GTGCAAGAAACACCGCAACAAGAT-3'; RFXAP-R, 5' -CTGCTGTTGTCTTTGCTCCAAAACT-3'; RFXB-F, 5' - CTCCCTGAAGCACTCCACCACTC-3'; RFXB-R, 5' - AGCAGGAAGCGAACGGTCTCAA-3'; RFXANK-F, 5' - AGACCTCATCCAGACCCAGCAGAC-3' and RFXANK-R, 5'-CTCGCTGCCGGTTGGTGAGA-3'. Controls consisted of RNA treated identically, but without the addition of reverse transcriptase ( $\mathrm{RT}-$ ). The integrity of the cDNA was confirmed by amplifying GAPDH as described previously (Suzuki et al, 2002). Samples $(10 \mu \mathrm{l})$ of the amplified products were then subjected to $2.5 \%$ agarose gel electrophoresis and stained with ethidium bromide.

\section{Flow cytometry}

Cells were incubated for $60 \mathrm{~min}$ at $4{ }^{\circ} \mathrm{C}$, first with anti-HLA-DR monoclonal antibody L243 (ATCC) and then with affinity-purified fluorescein-conjugated goat anti-mouse IgG + IgM (Kirkegaard and Perry Laboratories, Gaithersburg, MD, USA), after which they were analysed in a FACScan flow cytometer (BD Biosciences). At least 30000 viable cells were studied in each condition. The data were analysed using CELLQUEST software (BD Biosciences). 

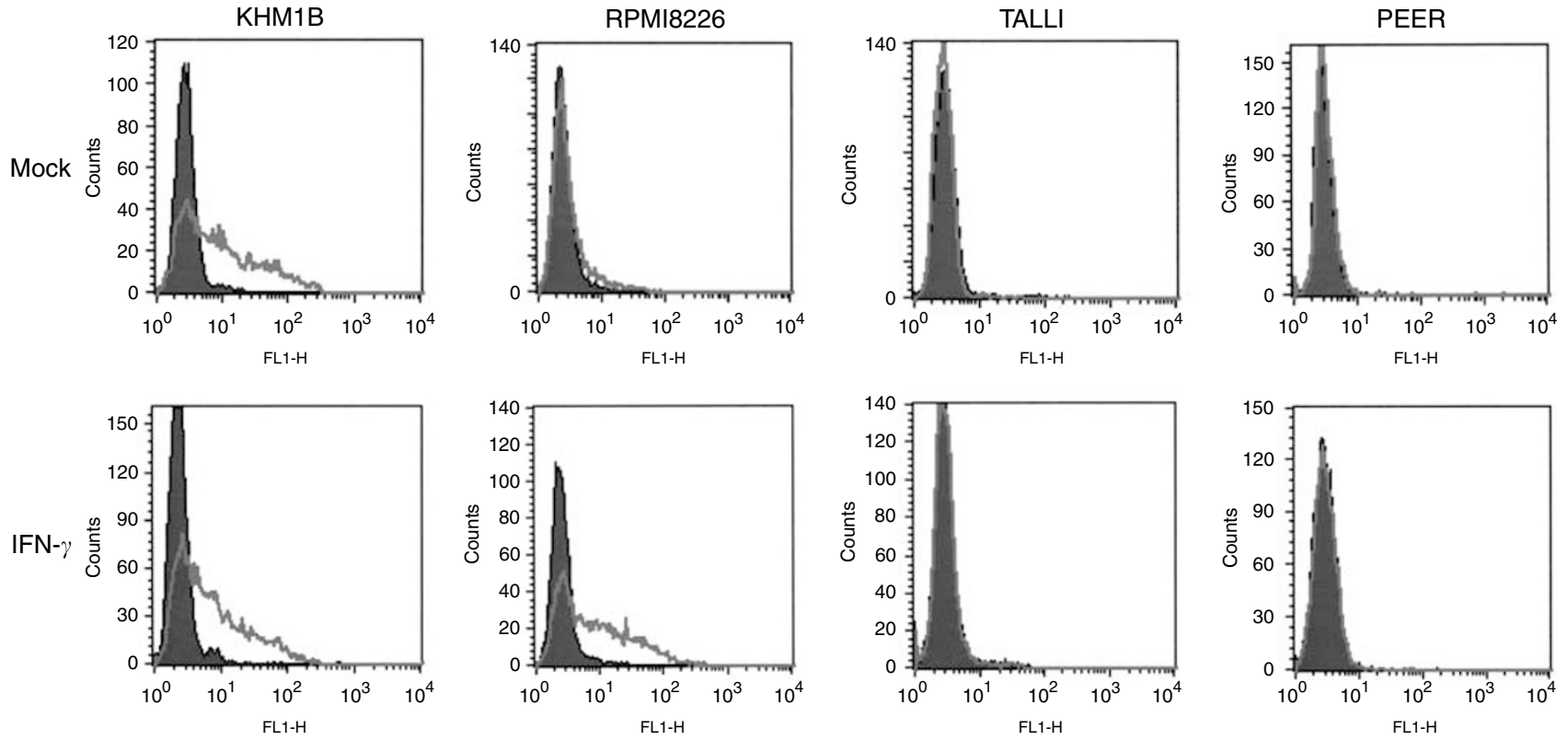

Figure 2 Cell surface expression of the HLA-DR protein in haematopoietic tumour cell lines. Cell lines were treated with either mock or $100 \mathrm{U}$ ml ${ }^{-1} \mid \mathrm{FN}$ $\gamma$ for $48 \mathrm{~h}$, after which HLA-DR expression was analysed by flow cytometry.

\section{Chromatin immunoprecipitation analysis (ChIP)}

Cells $\left(1 \times 10^{6}\right)$ were plated on 10 -cm dishes, incubated for $24 \mathrm{~h}$, and then treated with mock or $100 \mathrm{U} \mathrm{ml}^{-1}$ IFN- $\gamma$ for $48 \mathrm{~h}$. The cells were then exposed to formaldehyde, and chromatin was immunoprecipitated for $16 \mathrm{~h}$ at $4^{\circ} \mathrm{C}$ using antiacetylated histone $\mathrm{H} 3$ antibodies (Upstate Biotechnologies, Lake Placid, NY, USA). After immunoprecipitation, the DNA was recovered using agarose beads, incubated with Proteinase- $\mathrm{K}$ at $45^{\circ} \mathrm{C}$ for $1 \mathrm{~h}$, purified using the phenol/chloroform method, and precipitated with ethanol. PCR was carried out with approximately $1 / 100$ of the immunoprecipitated DNA using SYBR Green sequence detection reagents (Applied Biosystems) in a solution containing $100 \mathrm{ng}$ of DNA, $25 \mu \mathrm{l}$ of SYBR Green PCR Master Mix and $2.5 \mathrm{pmol}$ of each primer. The primers used were $5^{\prime}$-ACAAGCTCCCTGCAACTCAG-3' (CIITAChIP-F) and $5^{\prime}$-CCACCACGTGCTTTATCAGA-3' (CIITAChIP-R). In addition, the $5^{\prime}$ region of GAPDH was amplified as an internal control. The PCR cycling protocol entailed one cycle at $95^{\circ} \mathrm{C}$ for $5 \mathrm{~min}$ and 40 cycles at $95^{\circ} \mathrm{C}$ for $30 \mathrm{~s}$ and $60^{\circ} \mathrm{C}$ for $1 \mathrm{~min}$. Fluorescent signals were detected using an ABI 7000 Prism 7000 (Applied Biosystems), and the accumulation of PCR product was measured in real time as the increase in SYBR green fluorescence. Data were analysed using ABI Prism 7000 SDS Software (Applied Biosystems). Standard curves relating the initial template copy number to the fluorescence and amplification cycle were generated using the amplified PCR product as a template, and were then used to calculate the DNA copy number in each sample. Ratios of the intensities of the CIITA and GAPDH signals served as relative measures of the histone acetylation level of CIITA in each cell line.

\section{RESULTS}

\section{Expression of HLA-DR in haematopoietic tumour cell lines}

We initially examined the expression of HLA-DR in a group of haematopoietic tumour cell lines, with or without IFN- $\gamma$ treatment (Figure 1, summary in Table 1). RT-PCR analysis of 26 cell lines showed that 13 expressed HLA-DR constitutively; three expressed it following induction with interferon- $\gamma$; and 10 did not express it at all. None of the T-cell leukaemia cell lines expressed HLA-DR, while cell lines established from B-cell ALL, mature B-cells and Burkit lymphoma all showed constitutive or IFN- $\gamma$-inducible HLADR expression.

Flow-cytometric analysis showed HLA-DR protein to be present at the surface of cells that express HLA-DR mRNA constitutively (Figure 2, KHM1B) or after induction with IFN- $\gamma$ (RPMI8226). Conversely, surface expression of HLA-DR was not detected in cells that did not express HLA-DR mRNA (TALL1 and PEER), which indicates that the absence of surface HLA-DR protein was caused by loss of gene transcription, rather than by posttranscriptional alteration.

\section{Expression of the transactivator of MHC class II in haematopoietic tumour cells}

Bare lymphocyte syndrome (BLS) is a severe immunodeficiency caused by the absence of MHC class II molecules (Klein et al, 1993). Patients with this syndrome carry a defect in the genes encoding the components of the RFX complex and CIITA (Steimle et al, 1993; Villard et al, 1997; Masternak et al, 1998; Nagarajan et al, 1999). To determine the role of RFX and CIITA genes in the suppression of HLA-DR expression, we carried out RT - PCR with a group of haematopoietic tumour cell lines that either did or did not express HLA-DR (Figure $3 \mathrm{~A}$ and $\mathrm{B}$ ). We found ubiquitous expression of all the four RFX subunits in T-cell lines, irrespective of whether they expressed HLA-DR, and therefore excluded RFX inactivation as a cause of the MHC class II suppression (Figure 3B).

When we then examined the expressions of CIITA-PI, CIITAPIII and CIITA-PIV in each cell line (Figure 3A and Table 1), we found that, as expected, CIITA-PI mRNA was not expressed in any of the haematopoietic cells studied. T-cell ALL and myeloid leukaemia cell lines showed complete suppression of both CIITAPI and CIITA-PIII, five cell lines (Molt-4, CCRF-HSB2, CCRF-CEM, PEER and K562) expressed low or negligible levels of CIITA-PIV, and five (Jurkat, SupT1, TALL1, Molt-3, and KG1) did not express it at all. Class II transactivator-PII was not examined, as its function remains unknown.

Most of the cell lines derived from multiple myeloma showed constitutive expression of HLA-DR, which correlated with CIITAPIV expression. Class II transactivator-PIII was expressed in all 
A

T-cell ALL

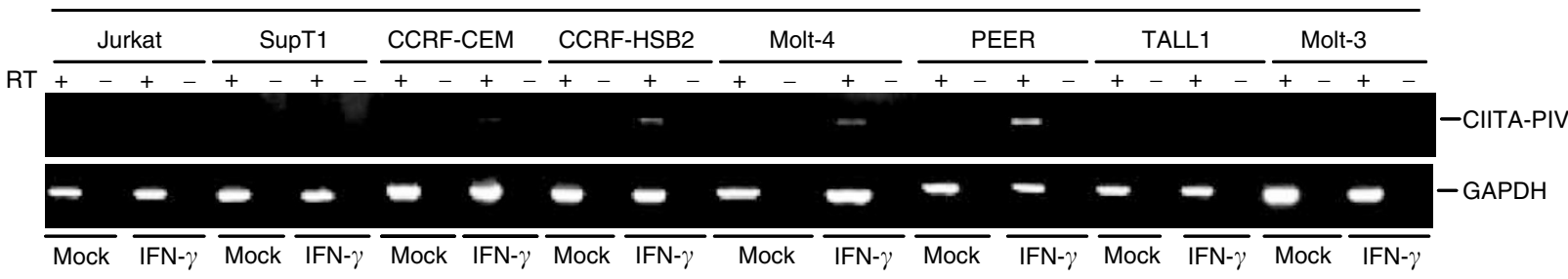

B-cell ALL

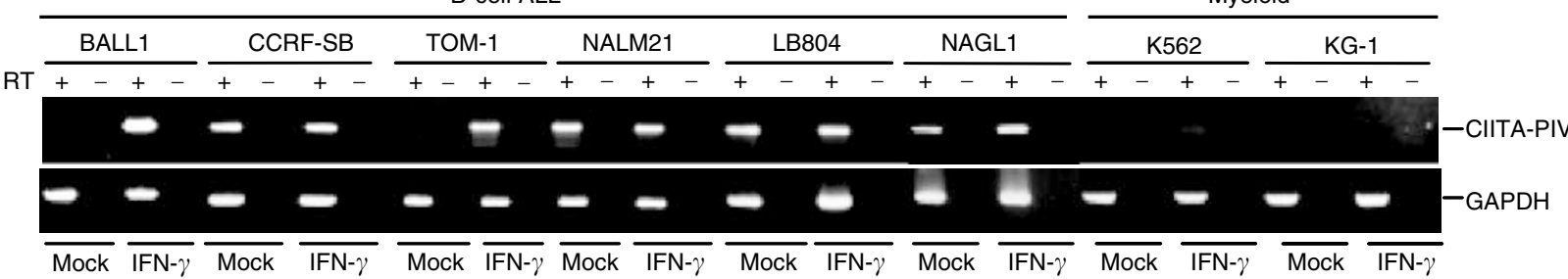

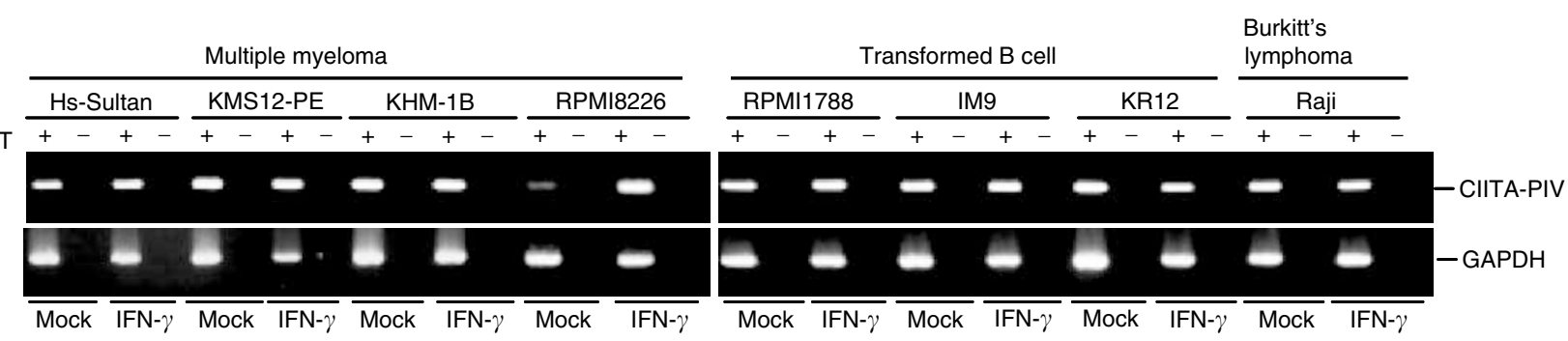

B

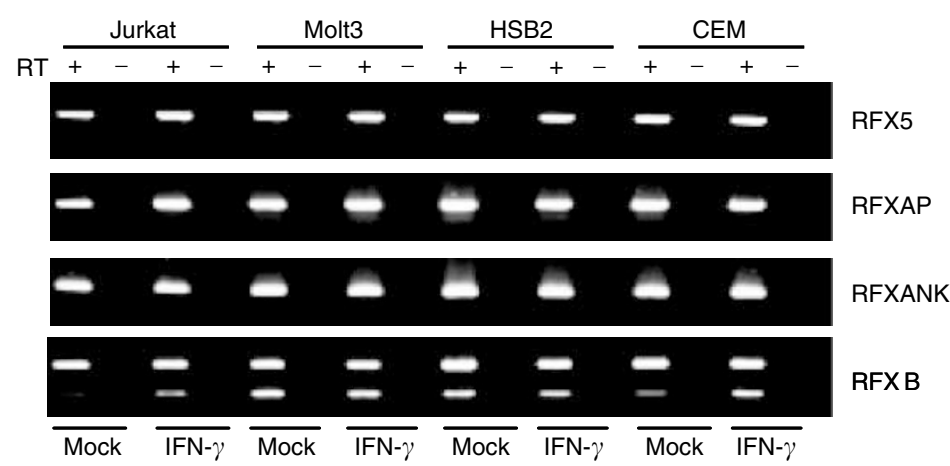

Figure 3 Expression of MHC class II transactivator in haematopoietic tumour cell lines. (A) RT-PCR analysis of CIITA expression in haematopoietic tumour cell lines. CDNA from cells treated with either mock or IFN- $\gamma$ for $48 \mathrm{~h}$ was amplified using primers that specifically amplify CIITA-PIV. The cell lines analysed are shown on the top. (B) RT-PCR analysis of RFX-5, RFX-AP, RFX-ANK and RFX-B in haematopoietic tumour cell lines.

transformed B-cells, but not in multiple myeloma cells (data not shown). One cell line, RPMI 8226, showed enhanced expression of HLA-DR and CIITA-PIV. This is thought to reflect both the IFN- $\gamma$ inducibility and CIITA-PIV dependence of HLA-DR expression in these cells. Thus, all of the cell lines from B-cell lineages showed strong constitutive and/or inducible HLA-DR expression.

\section{DNA methylation of CIITA-PIV}

We evaluated the possible involvement of DNA methylation in the silencing of the CIITA-PIV gene, using COBRA (Figure 4). Cell lines derived from T-cell ALL showed varying degrees of methylation: four (SupT1, Molt-4, PEER and TALL1) showed strong DNA methylation; three (Jurkat, CCRF-HSB2 and CCRFCEM) showed weak-to-moderate methylation and one (Molt-3) showed no methylation. By contrast, most cell lines of B-cell lineage, including multiple myeloma, show no CIITA-PIV methylation; two (TOM1 and RPMI8226) showed slight methylation. Two myeloid leukaemia cell lines (K562 and KG1) also showed methylation.

We then carried out DNA sequence analysis to assess the pattern of methylation in the CIITA-PIV locus using six cell lines, selected because they showed different degrees of methylation (Figure 5). Cell lines derived from T-cell ALL that do not express CIITA-PIV showed varying levels of DNA methylation in the region analysed. By contrast, no methylation was found in B-cell ALL (BALL1 and CCRF-SB). Careful examination of the pattern of methylation within the loci suggested that upstream regions are more densely methylated than downstream ones. 
A

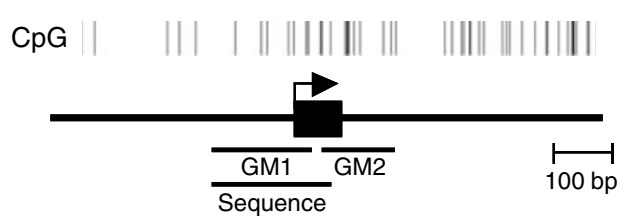

B
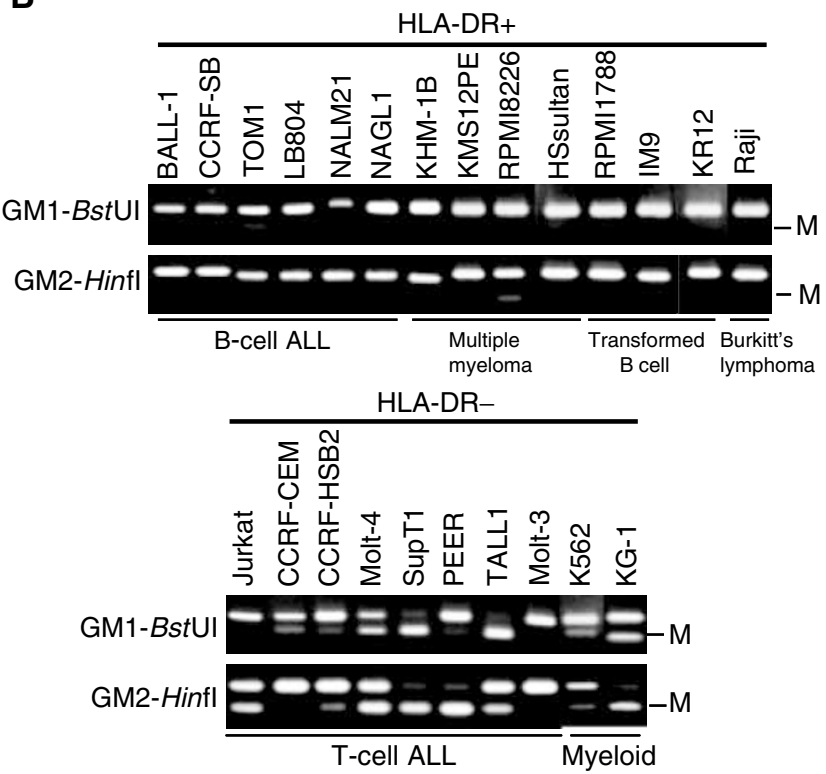

Figure 4 Analysis of CIITA methylation in haematopoietic tumour cell lines by COBRA. (A) CpG island of CIITA: exon I is indicated by the solid box; the transcription start site is indicated by an arrow; and the region analysed by bisulphite-PCR is indicated by a bar. (B) Aberrant methylation of CIITA in haematopoietic tumour cell lines. Cell lines are indicated on the top.

To confirm the role of DNA methylation in gene silencing of CIITA-PIV, two methylated cell lines (Jurkat and CEM) were treated with a methyltransferase inhibitor, 5-aza-dC, and/or IFN- $\gamma$. Although treating the cell lines with either 5-aza-dC or IFN- $\gamma$ did not restore expression of either CIITA or HLA-DR, combined treatment with both $5 \mathrm{aza}-\mathrm{dC}$ and IFN- $\gamma$ restored expression of both CIITA-PIV and HLA-DR (Figure 6).

\section{Histone deacetylation associated with DNA methylation- dependent CIITA gene silencing}

Deacetylation of histone is known to be associated with DNA methylation-dependent gene silencing (Nguyen et al, 2001; Suzuki et al, 2002). To determine the histone acetylation status in the CIITA locus, we carried out ChIP assays using antiacetylated histone H3 antibody (Figure 7). Overall, there was an inverse correlaion between DNA methylation and histone acetylation in CIITA-PIV. In unmethylated cell lines, levels of histone acetylation were high in the CIITA promoter region. In BALL1 and TOM1 cells, moreover, histone acetylation was induced by treatment with IFN $-\gamma$, indicating a role for histone acetylation in gene expression. By contrast, levels of histone acetylation remained low among cell lines that showed CIITA methylation, even after treatment with IFN- $\gamma$.

\section{Aberrant methylation of CIITA-PIV in primary AMLs}

To determine whether methylation of CIITA-PIV might be a feature of primary leukaemia, we carried out COBRA analyses using DNA from a group of AML specimens. Aberrant methylation of CIITA-PIV was detected in seven of the $32(22 \%)$ cases studied (Figure 8), whereas no methylation was detected in normal lymphocytes or bone marrow (data not shown). Thus, methylation of CIITA-PIV is not a cell line-specific phenomenon.

\section{DISCUSSION}

To explore the cause of the absence of MHC class II molecules in haematopoietic tumour cells, we examined the relationship between expression of HLA-DR and its co-activators (CIITA and RFX complex). Our results indicate that the CIITA-PIV expression is suppressed by DNA methylation of its $5^{\prime} \mathrm{CpG}$ island, which in turn leads to suppression of HLA-DR expression.

DNA methylation is known to be involved in the regulation of CIITA and MHC gene expression in several tumour cell types, including trophoblast-derived cells, a subset of lymphoma cells, and squamous cell carcinoma (Morris et al, 2000; Nie et al, 2001; Murphy et al, 2002; Moreau et al, 2003). Our results suggest that DNA methylation of CIITA-PIV is also a major cause of HLA-DR suppression in haematopoietic tumour cells, especially those derived from T-cells and myeloid cells. One exception was Molt3 T-cell leukaemia cells, which expressed no CIITA-PIV, even though the promoter region of the gene showed no methylation. Further study will be necessary to clarify whether epigenetic mechanisms other than DNA methylation - for example, histone modification (Jenuwein and Allis, 2001) - played a role in the silencing CIITA-PIV expression in those cells. In contrast to Tcells, most of those derived from B-cells showed strong constitutive or inducible HLA-DR expression. One plausible explanation is that constitutive expression of CIITA provides access to transcription factors that protect the $\mathrm{CpG}$ island from DNA methylation.

Although expressions of CIITA-PIV and HLA-DR were mutually exclusive, we did not formally exclude the possibility of an association between other CIITA promoters (e.g., CIITA-PIII) and the absence of MHC class II, and, indeed, CIITA-PIII can drive CIITA expression after IFN- $\gamma$ stimulation in a number of cell types, including endothelial cells, fibroblasts and melanocytes. But while the extent to which deregulation of CIITA-PIII is involved in the silencing of the HLA-DR gene awaits further investigation, the fact that the $5^{\prime}$ region of CIITA-PIII does not contain a CpG island makes it unlikely that DNA methylation plays a role in gene silencing.

MHC class II expression has been shown to be inversely related to tumorigenicity and directly related to immunogenicity of mouse L1210 lymphoma clones (Fuji and Iribe, 1986). Indeed, it is now known that the loss of MHC molecules is one of the mechanisms by which cancer cells escape host immunity (Garrido and Algarra, 2001). That most cells of B-cell lineage express HLA-DR, while those of T-cell lineage do not, may be one of the reasons for the difference in prognosis between B-cell and T-cell malignancies that is, leukaemias or lymphomas involving B-cell lineage generally have better prognoses than their T-cell counterparts. It is therefore noteworthy that epigenetic modifications are reversible, which may make them an effective target for therapeutic intervention. Although intensive chemotherapy remains the therapeutic mainstay for acute leukaemia, long-term cure rates with chemotherapy alone remain at approximately $50 \%$, creating an urgent need for better therapies. Clinical trials are currently underway to study the effects of DNA methylation inhibitors in both haematological malignancies (Lubbert, 2000) and solid tumours (Momparler et al, 2000).

Our data suggest that drugs able to reverse aberrant epigenetic modification harbour a therapeutic potential related to their ability to reactivate silenced MHC class II expression. In that regard, expression of HLA-G, an MHC class I molecule, was 

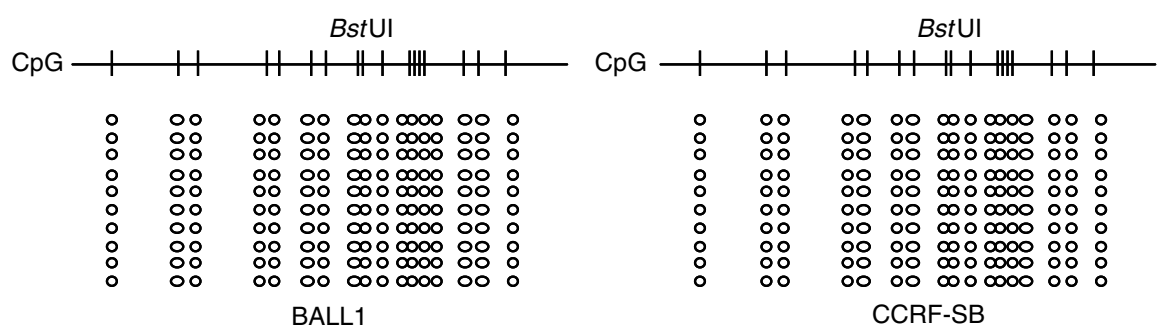

BstUI

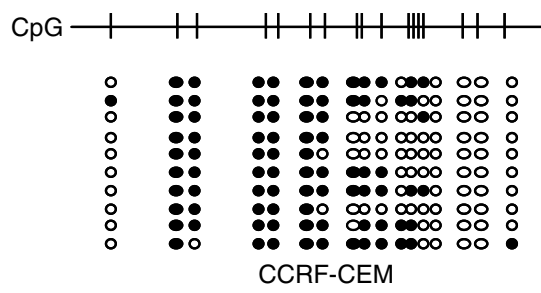

BstUI

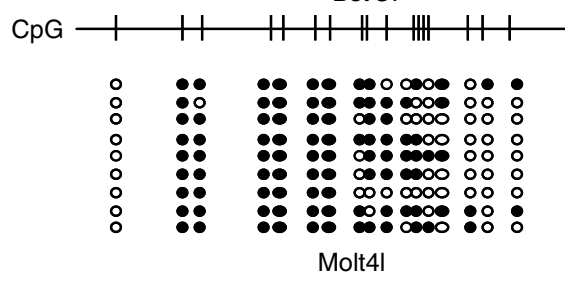

BstUI

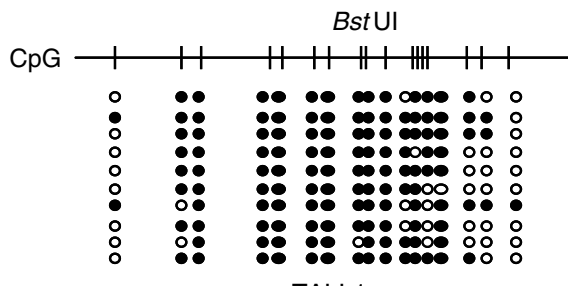

TALL1

Figure 5 Bisulphite sequencing of CIITA. Amplified PCR products were cloned into pCR4 vector using a TOPO-TA cloning Kit (Invitrogen) and plasmid DNA was purified. Sequencing reaction was performed using a Big-Dye terminator Kit (Applied Biosystems) and electrophoresed using an ABI3I00 system (Applied Biosystems). CpG sites are shown above. Methylated alleles are shown as solid circles; unmethylated alleles as shown as open circles.

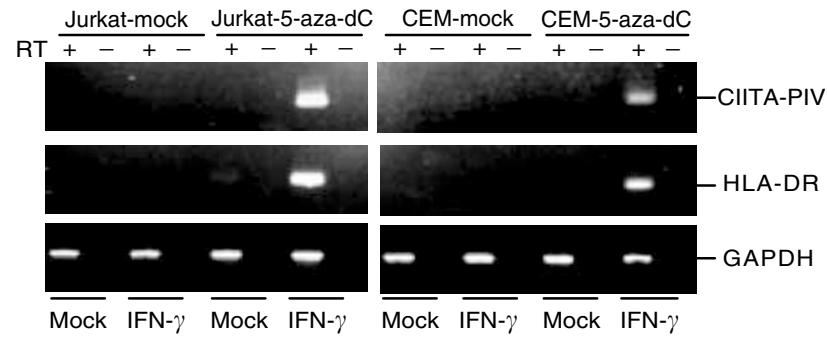

Figure 6 Restoration of IFN- $\gamma$-induced expression of CIITA and HLADR in methylated cell lines. RT-PCR was carried out using cDNA prepared from haematopoietic tumour cell lines treated with either mock, $100 \cup$ of IFN- $\gamma \mathrm{ml}^{-1}$ of for $48 \mathrm{~h}, \mathrm{I} \mu \mathrm{M} 5$-aza-dC for $72 \mathrm{~h}$ or I $\mu \mathrm{M} 5$-aza-dC and $100 \mathrm{U}$ of IFN- $\gamma \mathrm{ml}^{-1}$ for $48 \mathrm{~h}$.

previously re-established using a demethylating agent or histone deacetylase inhibitors (Moreau et al, 2003). Similar results might be expected in certain MHC class II-negative haematologic malignancies (e.g., T-cell ALL), perhaps leading to improved prognoses. Other genes that show aberrant DNA methylation of the promoter-associated CGI in T-cell ALL include p15, p73 and CABL (Garcia-Manero et al, 2002a, b). Similarly, an association may exist between CIITA-PIV methylation and poorer clinical prognosis. Further evaluation of this association would seem warranted.

The methylation around the transcription start site, which silenced CIITA-PIV gene expression, was in turn inversely related to histone acetylation, indicating a possible role for histone deacetylation in the gene silencing. This would be consistent with the findings of Morris et al (2002), who reported histone

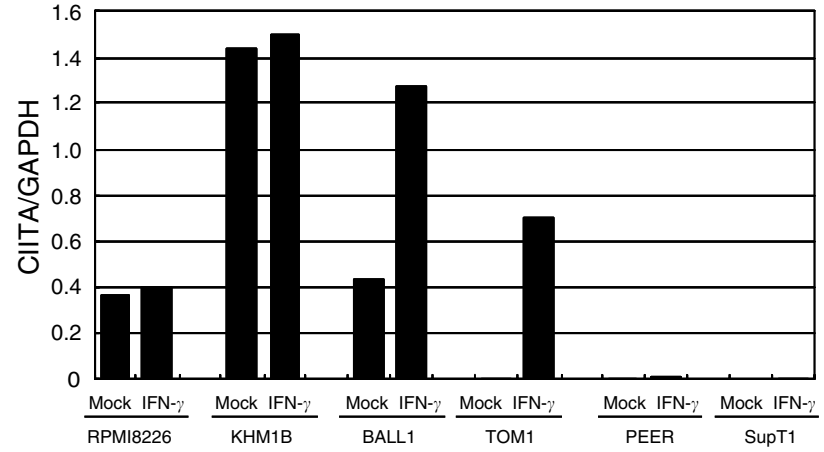

Figure 7 Real-time quantitative PCR analysis of acetylation of the CIITA locus in haematopoietic tumour cell lines. Chromatin immunoprecipitation analysis assays were carried out using antiacetylated histone $\mathrm{H} 3$ antibody after treatment with interferon- $\gamma$ or mock. Four cell lines that express CIITA (RPMI8226, KHMIB, BALLI and TOMI) and two cell lines that do not express (PEER and SupTI) were examined. Fluorescent signals were quantitated using an ABI7000 analysis system (Applied Biosystems). Bars depict the ratios of the intensities of the CIITA and GAPDH signals.

acetylation to be involved in the transcriptional regulation of CIITA.

Most multiple myeloma cell lines showed strong constitutive expression of HLA-DR. B lymphocytes constitutively express MHC class II genes; however, that expression is downregulated as they differentiate into plasma cells (Halper et al, 1978; Dellabona et al, 1989), reflecting diminished CIITA gene transcription (Silacci et al, 1994). Unexpectedly, myeloma cells, the malignant counterpart of plasma cells, showed constitutive MHC class II expression. 


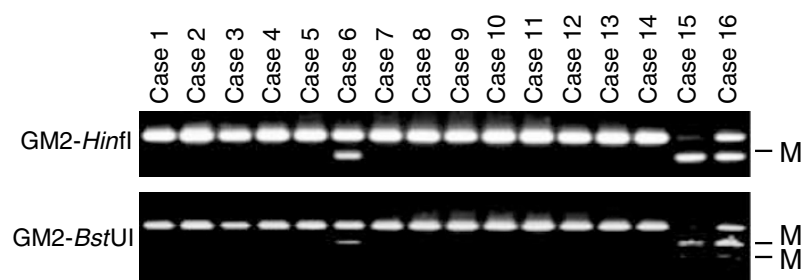

Figure 8 COBRA analysis of CIITA methylation in specimens of AML. Restriction enzymes and the region analysed are shown on the right. Case numbers are indicated on the top.

Apparently, during the neoplastic change from plasma to myeloma cells, they regain constitutive MHC class II expression. Nonetheless, CIITA-PIII, which normally directs constitutive MHC class II expression in B-cells, remained suppressed in all myeloma cell lines. In this case, constitutive HLA-DR expression was dependent on CIITA-PIV expression. This is of particular interest to us, because the dependence of constitutive MHC class II expression on CIITA-PIV has not been reported previously. As a consequence,

\section{REFERENCES}

Clark SJ, Harrison J, Paul CL, Frommer M (1994) High sensitivity mapping of methylated cytosines. Nucleic Acids Res 22: 2990 - 2997

Cresswell P (1994) Assembly, transport, and function of MHC class II molecules. Annu Rev Immunol 12: 259-293

Deffrennes V, Vedrenne J, Stolzenberg MC, Piskurich J, Barbieri G, Ting JP, Charron D, Alcaide-Loridan C (2001) Constitutive expression of MHC class II genes in melanoma cell lines results from the transcription of class II transactivator abnormally initiated from its B cell-specific promoter. J Immunol 167: 98 - 106

Dellabona P, Latron F, Maffei A, Scarpellino L, Accolla RS (1989) Transcriptional control of MHC class II gene expression during differentiation from $B$ cells to plasma cells. J Immunol 142: $2902-2910$

Fuji H, Iribe H (1986) Clonal variation in tumorigenicity of L1210 lymphoma cells: nontumorigenic variants with an enhanced expression of tumor-associated antigen and Ia antigens. Cancer Res 46: 5541-5547

Garcia-Manero G, Bueso-Ramos C, Daniel J, Williamson J, Kantarjian HM, Issa JP (2002a) DNA methylation patterns at relapse in adult acute lymphocytic leukemia. Clin Cancer Res 8: 1897-1903

Garcia-Manero G, Daniel J, Smith TL, Kornblau SM, Lee MS, Kantarjian HM, Issa JP (2002b) DNA methylation of multiple promoter-associated CpG islands in adult acute lymphocytic leukemia. Clin Cancer Res 8: $2217-2224$

Garrido F, Algarra I (2001) MHC antigens and tumor escape from immune surveillance. Adv Cancer Res 83: 117-158

Halper J, Fu SM, Wang CY, Winchester R, Kunkel HG (1978) Patterns of expression of human 'Ia-like' antigens during the terminal stages of $\mathrm{B}$ cell development. J Immunol 120: 1480 - 1484

Herman JG, Civin CI, Issa JP, Collector MI, Sharkis SJ, Baylin SB (1997) Distinct patterns of inactivation of p15INK4B and p16INK4A characterize the major types of hematological malignancies. Cancer Res 57: 837841

Jenuwein T, Allis CD (2001) Translating the histone code. Science 293: $1074-1080$

Jones PA, Baylin SB (2002) The fundamental role of epigenetic events in cancer. Nat Rev Genet 3: 415-428

Katzenellenbogen RA, Baylin SB, Herman JG (1999) Hypermethylation of the DAP-kinase $\mathrm{CpG}$ island is a common alteration in B-cell malignancies. Blood 93: 4347-4353

Klein C, Lisowska-Grospierre B, LeDeist F, Fischer A, Griscelli C (1993) Major histocompatibility complex class II deficiency: clinical manifestations, immunologic features, and outcome. J Pediatr 123: 921-928

Kraiba R, Loiseau P, Faille A, Poirier O, Piatier-Tonneau D, Degos L, Abita JP, Charron D (1989) HLA-DR and DQ antigens in chronic lymphocytic multiple myeloma cells showed expression of HLA-DR with no methylation in CIITA-PIV, perhaps making them a good target for $\mathrm{CD} 4+\mathrm{T}$-cells, which recognise antigen restricted by MHC class II molecules.

In summary, we have shown that the aberrant methylation of CIITA-PIV is associated with the silencing of CIITA-PIV and HLADR expression in T-cell ALL. As this epigenetic change may enable the cells escape from the host immune system, it may be a useful indicator of prognosis. Moreover, drugs that reverse such aberrant methylation would seem potentially useful in the treatment of Tcell ALL.

\section{ACKNOWLEDGEMENTS}

We thank Dr William F Goldman for editing the manuscript and Mutsumi Ohe-Toyota for technical assistance. This study is supported by grants-in-aid for Scientific Research on Priority Areas from the Ministry of Education, Culture, Sports, Science and Technology (MT, TT and KI). MT is supported by Mitsubishi Pharma Research Foundation. AS is a fellow from Japan Society for the Promotion of Science.

leukemia: dissociation of expression revealed by cell surface, protein, and mRNA studies. Leukemia 3: 386-393

Li Y, Nagai H, Ohno T, Yuge M, Hatano S, Ito E, Mori N, Saito H, Kinoshita $\mathrm{T}$ (2002) Aberrant DNA methylation of p57(KIP2) gene in the promoter region in lymphoid malignancies of B-cell phenotype. Blood 100: 2572 2577

Lubbert M (2000) DNA methylation inhibitors in the treatment of leukemias, myelodysplastic syndromes and hemoglobinopathies: clinical results and possible mechanisms of action. Curr Top Microbiol Immunol 249: $135-164$

Mach B (1999) Perspectives: immunology. Regulating the regulator. Science 285: 1367

Masternak K, Barras E, Zufferey M, Conrad B, Corthals G, Aebersold R, Sanchez JC, Hochstrasser DF, Mach B, Reith W (1998) A gene encoding a novel RFX-associated transactivator is mutated in the majority of MHC class II deficiency patients. Nat Genet 20: 273-277

Momparler RL, Eliopoulos N, Ayoub J (2000) Evaluation of an inhibitor of DNA methylation, 5-aza-2'-deoxycytidine, for the treatment of lung cancer and the future role of gene therapy. Adv Exp Med Biol 465: $433-$ 446

Moreau P, Mouillot G, Rousseau P, Marcou C, Dausset J, Carosella ED (2003) HLA-G gene repression is reversed by demethylation. Proc Natl Acad Sci USA 100: 1191-1196

Morris AC, Beresford GW, Mooney MR, Boss JM (2002) Kinetics of a gamma interferon response: expression and assembly of CIITA promoter IV and inhibition by methylation. Mol Cell Biol 22: 4781-4791

Morris AC, Spangler WE, Boss JM (2000) Methylation of class II transactivator promoter IV: a novel mechanism of MHC class II gene control. J Immunol 164: 4143-4149

Muhlethaler-Mottet A, Otten LA, Steimle V, Mach B (1997) Expression of MHC class II molecules in different cellular and functional compartments is controlled by differential usage of multiple promoters of the transactivator CIITA. EMBO J 16: $2851-2860$

Murphy SP, Holtz R, Lewandowski N, Tomasi TB, Fuji H (2002) DNA alkylating agents alleviate silencing of class II transactivator gene expression in L1210 lymphoma cells. J Immunol 169: 3085-3093

Nagarajan UM, Louis-Plence P, DeSandro A, Nilsen R, Bushey A, Boss JM (1999) RFX-B is the gene responsible for the most common cause of the bare lymphocyte syndrome, an MHC class II immunodeficiency. Immunity 10: 153-162

Nguyen CT, Gonzales FA, Jones PA (2001) Altered chromatin structure associated with methylation-induced gene silencing in cancer cells: correlation of accessibility, methylation, $\mathrm{MeCP} 2$ binding and acetylation. Nucleic Acids Res 29: 4598-4606 
Nie Y, Yang G, Song Y, Zhao X, So C, Liao J, Wang LD, Yang CS (2001) DNA hypermethylation is a mechanism for loss of expression of the HLA class I genes in human esophageal squamous cell carcinomas. Carcinogenesis 22: $1615-1623$

Ossendorp F, Toes RE, Offringa R, van der Burg SH, Melief CJ (2000) Importance of $\mathrm{CD} 4(+) \mathrm{T}$ helper cell responses in tumor immunity. Immunol Lett 74: 75-79

Piskurich JF, Wang Y, Linhoff MW, White LC, Ting JP (1998) Identification of distinct regions of 5' flanking DNA that mediate constitutive, IFNgamma, STAT1, and TGF-beta-regulated expression of the class II transactivator gene. J Immunol 160: 233-240

Scholl T, Mahanta SK, Strominger JL (1997) Specific complex formation between the type II bare lymphocyte syndrome-associated transactivators CIITA and RFX5. Proc Natl Acad Sci USA 94: 6330-6334

Silacci P, Mottet A, Steimle V, Reith W, Mach B (1994) Developmental extinction of major histocompatibility complex class II gene expression in plasmocytes is mediated by silencing of the transactivator gene CIITA. J Exp Med 180: 1329-1336

Steimle V, Otten LA, Zufferey M, Mach B (1993) Complementation cloning of an MHC class II transactivator mutated in hereditary MHC class II deficiency (or bare lymphocyte syndrome). Cell 75: 135-146

Suzuki H, Gabrielson E, Chen W, Anbazhagan R, van Engeland M, Weijenberg MP, Herman JG, Baylin SB (2002) A genomic screen for genes upregulated by demethylation and histone deacetylase inhibition in human colorectal cancer. Nat Genet 31: 141-149

Toyota M, Kopecky KJ, Toyota MO, Jair KW, Willman CL, Issa JP (2001) Methylation profiling in acute myeloid leukemia. Blood 97: $2823-2829$

Villard J, Lisowska-Grospierre B, van den Elsen P, Fischer A, Reith W, Mach B (1997) Mutation of RFXAP, a regulator of MHC class II genes, in primary MHC class II deficiency. $N$ Engl J Med 337: 748-753

Waldburger JM, Suter T, Fontana A, Acha-Orbea H, Reith W (2001) Selective abrogation of major histocompatibility complex class II expression on extrahematopoietic cells in mice lacking promoter IV of the class II transactivator gene. I Exp Med 194: 393-406

Wang RF (2001) The role of MHC class II-restricted tumor antigens and CD4+ $\mathrm{T}$ cells in antitumor immunity. Trends Immunol 22: 269-276

Wetzler M, McElwain BK, Stewart CC, Blumenson L, Mortazavi A, Ford LA, Slack JL, Barcos M, Ferrone S, Baer MR (2003) HLA-DR antigen-negative acute myeloid leukemia. Leukemia 17: 707-715

Xiong Z, Laird PW (1997) COBRA: a sensitive and quantitative DNA methylation assay. Nucleic Acids Res 25: $2532-2534$

Zhu XS, Linhoff MW, Li G, Chin KC, Maity SN, Ting JP (2000) Transcriptional scaffold: CIITA interacts with NF-Y, RFX, and CREB to cause stereospecific regulation of the class II major histocompatibility complex promoter. Mol Cell Biol 20: 6051-6061 